think I have proved my case as clearly as is possible in investigations of this kind. There are many difficulties to contend with in prosecuting these inquiries as the people in the neighbourhood of $\mathbf{B}-$ street \&c. are easily led in conversation, and without considerable tact and discretion the information obtained is practically useless. The epidemic being small my difficulties were fewer and consequently the information is more trustworthy.

A bottle of the beer was purchased by me for bacteriological purposes, and I have endeavoured, without success up to the present, to cultivate colonies of the typhoid bacilli by inoculating agar and peptone with drops of the beer. I can hardly look upon want of success in this direction, however, as damaging my case, considering the present uncertain knowledge we possess of the typhoid bacillus.

Leicester.

\section{FIVE CASES OF LAPAROTOMY PERFORMED ON PATIENTS OVER SEVENTY YEARS OLD.}

\section{BY J. RUTHERFORD MORISON, M.B. EdIN.,} F.R.C.S. EnG. \& EDIN.,

SENIOR ASSISTANT SURGEON, ROYAL INFIRMARY, NEWCASTLE-ON-TYNE.

Loxg lists of successful ovariotomies can no longer serve any good purpose, for it has been proved that the mortality of ovariotomy should not exceed 5 per cent. My excuse for publishing the following cases is the advanced age of the patients. Sir G. M. Humphry long since pointed ont that in old people repair and recovery are likely enough to follow major operations. This is true of abdominal section, - a fact not sufficiently recognised. My list includes all the patients over seventy on whom I have performed abdominal section, five in number. Four of them had ovariotomy successfully performed. Three of these are well and active at the present time. One died nearly two months after operation from the results of appendicitis. The fifth recovered from an exploratory abdominal section made to ascertain the nature of, and to treat if possible, an abdominal tumour of doubtful character and origin.

CASE 1.-A widow aged seventy was sent to me in December, 1890 , by Dr. McBean with a cystic tumour in the abdomen. For several months she had noticed a growing swelling, had lost flesh and strength, and had been troubled with a hæomorrhagic vaginal discharge. The patient was a thin, wirylooking old lady, very nerrous but cheerful. Nothing was found wrong except in the abdomen, which was distended to about the size of a six months' pregnancy. The distension was due to a fluctuating tumour fixed below in the pelvis. The left fornix was bulged by an elastic fixed tumour pushing the uterus over to the right. On Dec. 22nd, 1890, I rerformed the following operation. A broad ligament cyst was exposed, tapped, and enucleated after dividing the peritoneum covering it. The hæmorrhage was arrested by tying each bleeding point as exposed. A large raw surface was left, over which the stripped peritoneum was laid. The operation occupied one hour. Drainage was employed for three days. The patient recovered so rapidly trat she was allowed to get up on the tenth day, and went home well in a fortnight.

CASE 2.-A widow aged seventy-four came to me in August, 1892. 'The patient discovered an abdominal swelling herself ten years ago and consulted a medical man, who said it contained fluid. The swelling had steadily increased in size, but except by its weight had caused no discomfort. She had had no teeth since she was thirty years of age, and was never robust. All her family were short-lived. The patient was a thin, anxiouslooking woman with wrinkled skin and brown hair turning grey. Nothing was discovered abnormal except in the abdomen, which was rounded, prominent and larger than a full-time pregnancy. A large, well-defined cystic tumour was the cause of the swelling. It filled the abdomen so completely as to appear immovable, but friction could be felt over it on pushing it from side to side and during forced respiration. The tumour could be felt in front of and distinct from the uterus. On Ang. 6th, 1892, I removed a large cystic ovarian tumour free from adhesions. The after progress was uneventful. On the ninth day the dressings were taken off for the first time and the sutures taken out. The wound had entirely healed by first intention. On the fifteenth day the patient went home well.

CASE 3.-A widow aged seventy-two, under the care of
Dr. Oliver, seventeen months ago noticed a "lump" in the lower part of the bowels. There was no pain, but "the womb came down." Four months ago the tumour began tc increase in size and rapidly became larger. The uterus now troubled her and she noticed a coloured vaginal discharge which had increased during the last four or five weeks. The weakness produced by this was her chief complaint. Her health since she attained the age of forty-five years had been fair Up to that time she suffered from bilious attacks. She was a trim, bright-complexioned old lady with iron-grey hair ard a senile cataract in her right eye. Her heart was hypertrophied, as was shown by a diffused and heaving apex beat The arteries were rigid and tortuous ; the lungs were healthy. The urine was normal in quantity; sp. gr. 1005 ; a trace of albumen was present. The skin of the abdomen was muck pigmented, especially over the upper part, and the superficia veins were dilated. The abdomen was made prominent by : rounded cystic thin-walled tumour, flaccid and apparently unilocular, about the size of a large football. It was freek movable from side to side, but not from below upwards. 'Tht anterior wall of the vagina was prolapsed and the anterio: cul-de-sac filled by a rounded elastic tumour. The lef 1 fornix was bulged out by the swelling. On the right side $\varepsilon$ hard nodular swelling was connected with the tumour. The uterus lay behind and was free from the tumour. Or Sept. 8th, 1892, I performed the following operation. flaccid cyst of the right ovary containing about one gallon o very thick glairy fluid was removed. The left ovary, with hard tumour about the size of a walnut growing from it, wa also taken away and the abdominal wound entirely closed Subsequent progress was most satisfactory. The dressing wa: changed for the first time on the tenth day after the operation when the stitches were taken out. The wound healed b. first intention except at one place about half an inch long. where the skin had become inverted and granulations wer visible. This healed a few days afterwards. On the tent! day the patient left her bed, and on the fifteenth she wen home.

CASE 4.-A widow aged seventy-seven, a patient of $\mathrm{Dr}$ Munro of Barnard Castle. For years her abdomen ha been large. She was suddenly seized with pain in the righ iliac fossa, vomiting and shivering. The pain soon afterwasd extended to the right leg, preventing ber from straighterin it. The bowels had been confined and she had been feveris and sweating at nights during the whole illness. The da previous to my visit Dr. Munro and Dr. Drummond founc by means of a hypodermic syringe, fetid pus in the xigh iliac fossa. Thirty-three or thirty-four years ago she ha a dangerous illness-" inflammation of the bowels"--0 the right side. She had never been robust but usual healthy. The patient was a thin, dark woman, who looked if with high temperature, tender swollen abdomen and oedem tous legs; the right leg was more swollen than the left. A operation was performed on Sept. 20th, 1892. On openin the abdomen in the right linea semilunaris an ovaria tumour the size of a football was exposed and removed. N pus was found in it and there was nothing about it 1 account for the patient's serious condition. The cæcun which Drs. Munro and Drummond had suspected to be th cause of the mischief, was now examined. It was adherer to the parietes and a fluid collection could be felt bebin and to its outer side extending back to the loin. second incision above the centre of the crest of the iliu: allowed the escape of fully six ounces of fetid pus. TH anterior or ovariotomy wound was sutured and tl lateral wound drained with a glass-tube, each wour. being separately attended to and dressed. The ovari tomy wound never gave any trouble and quickly heale Until Oct. 8th the after progress was most satisfactor the general condition improved with return of appetit sleep and freedom from pain. On this date the glas tube could not be replaced by the nurse, Dr. Munro myself, and for the first time since the operation her evenir temperature was over $100^{\circ}$...-Oct. 9th: No discharge fro sinus ; evening temperature $103^{\circ} .-12$ th : A gush of $\mathrm{F}$ from sinus with lowered temperature.-Recurrences of similar sort took place till Oct. 20th, when a fresh tend lump was noticed. -25th : Under chloroform I freely oxer an abscess which extended from the iliac crest to the cost margin. The cavity appeared to be between the muscl of the abdominal wall and contained about four oun of pus. Improrement followed and the patient was ai to be out of bed. Soon, however, she relapsed, with so evening rise of temperature.-Nov. 5th : Dr. Munro suspe 
Ligg a further collection of pus we explored again under chloroform and found pus at the bottom of the first sinus in a large cavity. A counter-opening was made in the back, two full-sized indiarubber drainage-tubes were passed from the Eront openings through it and the cavity was irrigated. The patient never really rallied and died on Nov. 9th, 1892.

The following is extracted from Dr. Munro's post-mortem meport. An abscess cavity extended from the anterior surface of the bladder, which was covered with pus, outside the meritoneum, along the iliac fossa and upwards, to the under surface of the liver. The three openings made at different times all led into it. The second abscess cavity was between she obliquus internus and the transversalis muscles. No communication between the abscess sac and the peritoneum sould be discovered, but from eight to ten ounces of pus were found in the pelvis and the intestines were glued together with purulent lymph. The cæcum and a portion of the ascending colon and ileum, with some surrounding tissue, were sent to me for dissection. The appendix vermiformis was rlued to the posterior surface of the cæcum and the ascending colon. About half an inch from the cæcum it was perforated by a ragged ulcer. The perforation opened into the abscess cavity. The ulcer had nearly cut off the distal from the proximal end of the appendix. Both portions were aervious. No concretion was found.

CASE 5. - A woman aged seventy was admitted to the Royal Infirmary, Newcastle-on-Tyne, on Aug. 20th, 1892, comlaining of painful swelling in her bowels and weakness. even weeks before admission she first felt ill ; she took to aer bed five weeks ago ; she then had some pain on the right ide of the abdomen. Three weeks before admission a painful ender swelling was discovered by Mr. Martin of North shields on the rioht side. Some diarrhoa was the only ther symptom. She was a florid, cyanosed, stout woman, oking extremely ill. Rapid feeble pulse ; temperature $106^{\circ}$ 10 appetite; dry tongue; considerable abdominal pain. Bronchial râles were detected on auscultation. The heart vas hypertrophied. A systolic mitral murmur could be eard. The urine was normal in quantity and quality. The bdomen was distended and tender. On the right side there was large, rounded tumour in the iliac fossa extending to the aiddle line below, to midway between the umbilicus and the nterior superior spine at the upper and inner border and above eaching to the lower costal margin. The patient was so ill nd the abdomen so tender that no satisfactory examination vas possible. From this time she improved, her temperature scillating between $98^{\circ}$ and $102^{\circ}$. The lung condition cleared tp and she gained a little strength, though still very weak und ill. The mass on the right side softened and showed a endency to point. No diagnosis could be made. On sept. 1st, 1892, I opened the abdomen in the middle ine, and introducing my hand found the bulk of the umour to be a retro-peritoneal malignant mass surrounding nd involving the cæcum. The pointing swelling was now unctured with a hypodermic needle in the right iliac ossa and pus was discovered. The median wound was closed nd dressed and a drainage-tube left in a separate opening or the abscess cavity. The patient was returned to bed pparently no worse for the operation. The median wound ealed in three weeks without any trouble. During Septemer and the first half of October she improved in condition, lough profuse suppuration continued, and she was once out bed. Then symptoms of increased cardiac failure showed emselves in breathlessness and cedema of the legs. On ct. 30 th, 1892, she complained of pain in the left leg, which as noticed to be discoloured at its most dependent parts like ost-mortem lividity. On the following day some of these ddened patches had turned black and there was no sensaon in the foot and leg or pulsation in the arteries. On ov. 2 nd, in the evening, she died somewhat suddenly. efore death total gangrene of the leg had occurred. ecropsy: There was contraction of the mitral orifice of a pertrophied heart. No vegetations were detected on any the valves. The left femoral artery was blocked for about $\varangle$ inches with an adherent blood-clot, white in the centre id red at the ends. There was a large malignant mass of ands behind the cæcum and surrounding it. The interior the cæcum was extensively ulcerated, the ulcer having ick, hard walls. At the outer side and behind the cæcum d ascending colon a large abscess cavity, extending from e pelvis to the under surface of the liver and diaphragm, is found. No secondary deposits were observed. Examined croscopically the growth proved to be a cylindroma. aville row, Newcastle-on-Tyne.

\section{THREE CASES OF INTRA-OCULAR TUMOURS. ${ }^{1}$}

BY S. JOHNSON TAYLOR, M.B., C.MI. EdIN. \&c.

CASE 1.-A man aged sixty stated that, two months before consulting me, he had experienced a flickering in his left eye, followed in three days by a loss of vision in the same organ; there was no pain or other disturbance. The sight of his right eye was fairly normal, whilst that of the left was less than counting fingers; the left pupil was a little larger than the right and only acted very slightly to light; the tension was normal or a full normal. The episcleral vessels in the middle line below were much enlarged and by focal light a dark-brown mass far forwards was seen inferiorly, and by careful focussing with the ophthalmoscope some small vessels could be seen on its surface, whilst to its nasal side the retina was clearly detached, its vessels being seen with a convex lens of five dioptres. There was no evidence of any inflammatory mischief, nor did the mass move in any way with change of position, and it could clearly be accounted for only on one theory-viz, that of new growth; a gumma, a cysticercus, or a tubercular mass were all readily excluded. The great enlargement of the episcleral vessels over the site of the tumour was noteworthy. Such vascular dilatation is frequently found in growths of and near the ciliary region and is a very important sign ; it occurred also in the next case. I urged the patient to allow his eye to be enucleated, but to that he would not consent. Some months afterwards I heard that the eye had been removed, but what valuable time was lost. No doubt secondary glaucoma, with intense pain, came on as the growth increased in size, and he submitted to the operation; the tumour was in all probability a melanotic sarcoma. Such a case is not uncommon. The next two cases are rare, one being exceptionally so.

CASE 2.-A woman aged sixty gave a history of increasing dimness of vision of the right eye since October, 1890, and was first seen by myself in September, 1891, when I found the vision 16 Jaeger with difficulty; the pupil, which acted to light, was oval horizontally, the iris tissue at its periphery above and below was gone and replaced by a patch of dark pigment; there were some large congested vessels on the sclerotic, one especially so below ; the tension was normal. The pupil dilated badly with a mydriatic; the lens was so cataractous that only a dim view of the fundus could be obtained ; but looking very obliquely with the opthalmoscopic mirror at the extreme periphery above and below the fairly regular, rounded outline of a dark mass could be seen, though no vessels could be detected on it and no details made out. Three days later I excised the eye, dividing the nerve far back, and up to the present-an interval of more than fifteen months-she has remained quite well. On opening the eye two separate growths in the ciliary region, one above, the other below, were seen, each about the size of half a cherry stone. A full report by Mr. Collins of the microscopical examination will be found in the twelfth volume of the Transactions of the Ophthalmological Society.

CASE 3. - This case, that of a woman aged fifty-two, is also a very unusual one, and I must confess I have never seen anything like it. There is no history of syphilis or tumours, but she has had acute rheumatism three times; she has had eleven children, of whom nine are living. About ten years ago, after a fright, the sight of her right eye was noticed to be defective, almost as much soasit is at present; of late she has had a feeling described as " misery" at the back of her head. I first examined her in November, 1891, when the vision was only perception of light, with the pupil, anterior chamber and tension normal. Ophthalmoscopic examination revealed a rounded, well-defined, greyish-white, solid-looking mass occupying the centre of the fundus, completely obscuring the optic disc and yellow spot and coming forward in front of the retina into the vitreous, so that its most anterior part could be seen clearly with a convex lens of twelve dioptres. It could be isolated on all sides, above, below, rigbt and left, and the retinal ressels at several points could be seen emerging from beneath it; its surface in parts was stippled with a slategrey pigment and at one or two points patches of newly formed vessels, arranged in no definite way, could be made

I Abstract of a paper read before the Norwich Medico Chirurgical Society on Dec. 6 th, 1892 . 